\title{
Vivencia del cuidado de enfermería en un proceso de duelo
}

\section{Nursing care experience in a grieving process Experiência da assistência de enfermagem em um processo de luto}

\author{
Luzmila Hernández Sampayo ${ }^{1}$
}

${ }^{1}$ Enfermera Magister Materno Infantil, Profesora Asociada Universidad del Valle

Cómo citar este artículo en edición digital: Hernández, L. (2019) Vivencia del cuidado de enfermería en un proceso de duelo. Cultura de los Cuidados (Edición digital), 23 (54). Recuperado de

http://dx.doi.org/10.14198/cuid.2019.54.07

Correspondencia: Carrera 43 numero 6. --115 Cali Valle

Correo electrónico de contacto:Luzmila.hernandez@correounivalle.edu.co Recibido: 23/11/2018; Aceptado: 12/03/2019

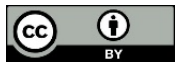

\section{ABSTRACT}

Perinatal death from an institutional view is a matter of difficult confrontation for both, parents who experience the loss, as for the health personnel present at the event. Kristen Swanson theory considers that the goal of nursing is to provide care, for women and her family, significantly to help in the acceptance of the death of a loved one. The support health personnel provide for parents and their family, is significant in the acceptance of the loss and the development of the grieving process. This article tells the experience of a nurse in her interaction with a woman who faced the death of his daughter at the time of birth. It is analyzed based on the Kristen Swanson Care Theory, focuses on the meta-paradigmatics elements and processes or categories of care.

Keywords: Nursing theory, nursing care, perinatal death.

\section{RESUMO}

Morte perinatal a partir de uma visão institucional é uma questão de confronto difícil para ambos, os pais que sofrem a perda, como para os profissionais de saúde presentes no evento. Teoria Kristen Swanson considera que a meta da enfermagem é a prestação de cuidados, para as mulheres e sua família, de forma significativa para ajudar na aceitação da morte de um ente querido. Os profissionais de saúde de apoio fornecer aos pais e sua família, é significativa na aceitação da perda e para o desenvolvimento do processo de luto. Este artigo conta a experiência de uma enfermeira em sua interação com uma mulher que enfrentou a morte de sua filha no momento do nascimento. Analisou baseia-se na Teoria do Cuidado Swanson Kristen, incide sobre os elementos e processos ou categorias de cuidados de meta-paradigmáticas.

Palavras chave: Teoria de enfermagem, cuidados de enfermagem, morte perinatal. 
La muerte perinatal desde el ámbito institucional es un hecho de difícil confrontación tanto para los padres quienes experimentan la pérdida, como para el personal de salud que presencia el evento.La teoría de Kristen Swanson, considera que la meta de la enfermería es brindar cuidado a la mujer y su núcleo familiar, de manera significativa para ayudarla en la aceptación de la muerte de un ser querido. El apoyo que el personal de salud brinda a los padres y la familia, es significativa en la aceptación de la pérdida y la elaboración del duelo. El presente artículo relata la experiencia de una enfermera en su interacción con una mujer que afronto la muerte de su hija al momento de nacer. Se analiza con base en la teoría de los cuidados de Kristen Swanson y se centra en los elementos metaparadigmáticos y los procesos o categorías del cuidado de enfermería.

Palabras clave: Teoría de enfermería, cuidado de enfermería, muerte perinatal.

\section{INTRODUCCIÓN}

Uno de los acontecimientos especiales en la vida de una familia es el nacimiento de un hijo. Desde el embarazo hasta el momento del nacimiento, se desarrollan sentimientos de esperanza, ilusión, considerando siempre que todo culminara satisfactoriamente. Sin embargo, no todos los embarazos terminan acorde a lo esperado. Según Maroto, García y Mateo (2004), generalmente, los padres se sienten responsables de la protección de sus hijos/as y la muerte de un hijo suele ser vivida con sentimientos de fracaso y con una gran culpabilidad. La muerte de un hijo conlleva además otras pérdidas significativas como los sueños, expectativas, identidad, roles, esperanzas y proyectos para el futuro. Durante muchos años, cuando los profesionales de salud se encontraban ante una muerte perinatal, lo más habitual era que la madre fuera sedada $\mathrm{y}$, al nacer el bebé se le retiraba lo antes posible de la sala de parto. De este modo se pretendía evitar o reducir el dolor de la madre por la muerte de su bebé. Se pensaba que lo mejor era que no tuviese ningún contacto con el hijo fallecido, eliminar cualquier indicio de su existencia y evitar así que formara algún tipo de apego con él, por mínimo que fuera López García (2011). Algunos trabajos de investigación han demostrado que ésta no es la forma más conveniente de actuar, ni la más humana. El primer artículo sobre el sufrimiento de los progenitores apareció en 1959 (Elia, 1959,. "The management of grief situations in obstetrics"), el cual recogía las dificultades del obstetra frente a la muerte fetal antes, durante y después del parto, hacía recomendaciones humanistas sobre su abordaje y la atención a la pareja y mencionaba la pena del propio médico. Sugería informar a la madre acerca del parto y el bebé cuando despertase de la anestesia, pero no hablaba de verlo o tomarlo en brazos.

A finales de los años 60, el duelo perinatal o neonatal fue adquiriendo importancia a nivel clínico y científico, con la publicación del artículo "Los efectos psicológicos del mortinato sobre las mujeres y sus médicos", su autor (Burne, 1968), describió los efectos psicológicos de la perdida sobre las mujeres y planteó el concepto del ángulo ciego, para referirse a la recomendación médica de pasar por el trance simulando que nada había sucedido, pues el objetivo era que los progenitores olvidaran cuanto antes lo sucedido y buscaran rápidamente un nuevo embarazo. Más tarde, Kennell, Slyter y Klaus (1970) publican “La respuesta de luto de los padres por la muerte de un hijo 
neonato". El estudio determinó seis tipos de respuesta al duelo: tristeza, pérdida del apetito, incapacidad para dormir, preocupación, irritabilidad e incapacidad para reanudar las actividades cotidianas.

Kirkley-Best y Kellner (1982), criticaron la bibliografía previa por sus errores metodológicos concluyendo que "sin un estudio apropiado, los profesionales están destinados a seguir las modas de los libros populares sobre duelo, sin llegar a cubrir las necesidades específicas de los padres que vivían la pérdida"; lo denominaron el duelo olvidado. Recomendaron entonces que los progenitores vieran y tomaran en brazos al bebé muerto y propusieron desarrollar grupos de apoyo para los padres afectados. Estudios más recientes como el realizado por Toledo y colaboradores en el año 2004, encontraron que muchos padres manifestaron tras la muerte de su hijo, su deseo de verlo o incluso acariciarlo. Sin embargo, una minoría lo considera como algo muy desagradable y no se encuentran preparados para tener contacto con el hijo muerto, sobre todo si el niño presenta alguna malformación o no se encuentra en buen estado. Aunque el contacto físico con el hijo o tener acercamiento a los objetos relacionados con él son elecciones que ayudan a muchos padres a desarrollar de manera adecuada el proceso de duelo, estas acciones no son elegidas por todos los padres por lo que no se debe nunca presuponer o limitar las elecciones paternas respectos a las conductas tras la muerte perinatal.

La Academia Americana de Pediatría en la década de los 1970 propuso protocolos para las intervenciones ante el duelo y para ayudar a las familias a encontrar un significado apoyándolas durante su pena. Los programas de duelo garantizan una atención de calidad para las familias, ofreciendo rituales como bautizos, toma fotografías y de huellas, mechón de cabello y otros.

El presente artículo relata la experiencia de una enfermera en su interacción con una mujer que afrontó la muerte de su hija al momento de nacer. Esta experiencia se analiza con base en la teoría de los cuidados de Kristen Swanson, centrándose en los elementos metaparadigmáticos y los procesos o categorías del cuidado. Esta es una teoría de rango medio que sustenta el fenómeno del que hacer de enfermería y hace que las intervenciones respondan a las necesidades del sujeto receptor del cuidado (Duran, 2016).

\section{SITUACIÓN DE ENFERMERÍA}

Una mañana de septiembre llegue, como docente de práctica clínica, al servicio de Alto Riesgo Obstétrico, con estudiantes de Enfermería. Iniciando el turno ingresa una paciente llamada María de 28 años de edad; su rostro reflejaba una tristeza infinita, la enfermera que la acompañaba comentó que es una paciente con un abrupcio placentario más preeclampsia severa, que acaba de tener una perdida perinatal, con 38 semanas de gestación y no aceptaba que le realizaran ninguna intervención. En ese momento, sentí que debía estar al lado de esta mujer y le pedí a la enfermera del servicio que me permitiera hacerme cargo de ella. Caminé hacia la habitación de María sin saber que iba a decirle, le pedí a Dios que me ayudara a encontrar las palabras adecuadas para dirigirme a ella. Me le acerque, me presenté y le dije: "estoy aquí para ayudarte"; ella sin ni siquiera abrir sus ojos me dijo: "yo sólo quiero irme a casa, no quiero nada más".

Le pregunté: “¿en quién crees?”. A lo que respondió: "creo en Dios, soy cristiana"; la siguiente pregunta fue: “¿tienes más hijos?”, 
"si uno de 13 años". Empecé a hablarle de las pruebas que Dios nos pone, que Él le había regalado por 38 semanas una bebé y había tenido la oportunidad de tenerla y amarla por ese tiempo. Le hable de lo importante que era que se dejara cuidar para que recuperara la salud. Le tome una mano y le dije: "es un momento muy difícil y sólo tú puedes sentirlo". El silencio nos invadió en un momento. Yo sin saber qué más decir, seguía tomándola de la mano; ella sin decir nada, sólo lloraba. Pasaron unos minutos y de repente abrió sus ojos y me dijo "me dejo atender si lo hace usted". Procedí a iniciar el tratamiento indicado y a tomar los exámenes de laboratorio, ella se mostró receptiva. Para mí Fue un momento especial e importante, donde se pone a prueba toda la sensibilidad que posees como ser humano, como enfermera; saber que está en tus manos comprender de manera respetuosa al otro en un momento tan difícil. Se terminó el turno, volví a la habitación para despedirme, ella me miró, se observaba con una gran vulnerabilidad, no dijo nada y yo sólo prometí que volvería al siguiente día.

A la mañana siguiente, la Enfermera que entregó el turno comentó sobre la mujer llamada María que había ingresado el día anterior, que estaba muy deprimida, que su signos vitales se encontraban muy inestables, que además había tenido una pérdida importante de sangre durante el parto y había que transfundirle dos unidades de glóbulos rojos. De inmediato me ofrecí a cuidarla durante el turno, y junto con un estudiante iniciamos las actividades de enfermería.

María se encontraba silenciosa y con una mirada triste. Noté en su expresión, signos de cansancio y deduje que no había dormido suficiente. La saludé, le comenté que esa mañana cuidaría de ella; sólo esbozo un "gracias". Inicié junto con el estudiante las actividades generales de enfermería. Solicitamos al banco de sangre las dos unidades de glóbulos rojos, y nos respondieron que en una hora las recibiríamos. El turno transcurría y, a mitad de éste, María recibe la visita de su madre quien le comenta que le entregarán el cuerpo de la niña en poco tiempo. Esto implicaba que esa misma tarde se realizaría el sepelio. Esta noticia conmocionó a María y comenzó a llorar de forma inconsolable. Manifestaba insistentemente que sólo deseaba irse a su casa para tener la oportunidad de despedirse de su niña.

La situación se complicó pues María, a partir de ese instante, nuevamente empezó a negarse a que se le realizaran cualquier procedimiento. Sólo rogaba que la dejáramos ir para ver por última vez a su hija. En ese momento, la abordó el obstetra y los residentes de ginecología de la sala pero ella seguía negándose rotundamente a recibir los cuidados.

Me le acerqué y le coloqué una mano en el hombro, sin saber cómo hablarle, sin saber que decirle; de repente me salieron las palabras: "voy a ayudarte para que te despidas de tu hija, pero antes debes recibir la transfusión", ella aceptó. Me propuse, en una carrera contra reloj, buscar en el hospital un espacio donde se pudiera llevar a cabo la despedida que María deseaba fervientemente. Como es de suponer, este tipo de situaciones en una institución de salud de nivel III, ni se permiten ni forman parte de los protocolos de atención. No obstante, la necesidad de María de despedirse de su hija y mi palabra empeñada para ayudarle fueron suficientes incentivos para procurar, a pesar de las barreras institucionales llevar a cabo la despedida. Varias personas me ayudaron, incluso corriendo el riesgo de ser amonestadas, para que no sólo el cuerpo de 
la niña fuera retirado de la morgue sino también que una oficina del servicio sirviera de sala provisional para que María acogiera en sus brazos por última vez a su pequeña.

En esa carrera que emprendí encontré personas que seguramente nunca hubiera pensado estaban tan dispuestas a ayudar a María. El sitio destinado para la despedida finalmente fue una oficina en la cual se podía garantizar la privacidad suficiente para que se realizara el ritual de despedida. Acomodé unas sillas para que se sentaran, además de María, su madre, su esposo y una hermana, el estudiante y yo.

Cuando María llegó a éste recinto le dije que era un momento muy especial donde debía mostrar serenidad y llenarse de fuerzas para despedir de la mejor forma a su hija. Llegaron los familiares con el cuerpo de la niña, nos tomamos todos de las manos e hicimos una oración. Seguidamente, tomé la niña y la puse en sus brazos.

Fue un momento conmovedor: María fijo su mirada en la cara de la niña, sonrió con infinita ternura, la estrechó contra su pecho, la besó muchas veces y solicitó que se hiciera el bautizo a su niña. Seguidamente conseguí agua y realicé el ritual; María hizo una oración y se la entregó a Dios. Retiré suavemente el cuerpo de la niña, se la entregué al familiar y nos fuimos con María al servicio donde estaba hospitalizada. Cuando llegamos, María me agradeció, yo de mi parte experimente la satisfacción de haber cumplido con creces una misión.

Esta experiencia me permitió reafirmar que el cuidado involucra además de los aspectos científico-tecnológicos de Enfermería valores como el respeto, la solidaridad y la compasión que le permiten a la enfermera sentir y compartir con el otro los momentos de dolor. Pude vivenciar también que el cuidado está lleno de instantes que nos pueden impulsar a la creatividad para favorecer soluciones sencillas a problemas complejos como el que María estaba viviendo por la muerte de su pequeña hija.

\section{ANÁLISIS POR PATRONES DE CONOCIMIENTO}

Bárbara Carper (1978), propuso Los patrones de conocimiento, los cuales hacen parte del componente científico de la práctica de enfermería, de tal forma que aumentan su complejidad epistemológica. Por lo tanto, cada patrón pretende dar una orientación de los problemas y las preguntas que a diario se enfrentan en el cuidado de enfermería. Esta autora propone cuatro patrones: empírico, estético, personal y ético. Años después, Chinn y Kramer (1999) proponen el patrón emancipatorio.

\section{Empírico:}

Se reconoce y comprende la condición física y emocional de María. Por su expresión se reconoce el dolor, la angustia y la tristeza. La narrativa muestra que la mujer presenta señales de insomnio y que además de tener afectada su parte emocional tiene compromiso de su salud física por la pérdida de sangre durante el parto. La situación describe una enfermera que llega a María, posicionándose muy bien en su rol de cuidador e identifica prioridades en el cuidado y ofrecerle alivio a su padecimiento.

\section{Conocimiento estético:}

Este patrón nos revela el arte de lo que es "ser una Enfermera/o", nos muestra la belleza y el significado de atender a una persona que necesita del cuidado. Se revela en la narración, puede darse al reconocer el significado que da a la expresión del rostro de la mujer y la incapacidad de dejar que le proporcionaran cuidado. Con su actuación la enfermera logra ganarse la confianza de 
María, a tal punto de pedirle que sólo se deja cuidar de ella.

\section{Conocimiento personal:}

La enfermera tiene una actitud de apertura con María. Tiene una experiencia intersubjetiva que le permite conocer y dar un significado especial al rostro de sufrimiento del paciente, su angustia $\mathrm{y}$ lágrimas. La enfermera aborda este tipo de conocimiento siendo sensible al padecimiento de la mujer y siendo además espontáneos al actuar. Los resultados se ven en la respuesta de María que muestra los efectos terapéuticos del toque amoroso que la enfermera aplica al conocer su situación.

\section{Conocimiento ético:}

Componente moral de la enfermería. La profesional basada en sus principios $\mathrm{y}$ valores orienta su ejercicio y la toma de decisiones deontológicas en el cuidado integral. En la narrativa el principio de beneficencia se observa claramente. Igual la obligación moral para actuar en beneficio del paciente, además Vemos a una enfermera moralmente $y$ éticamente comprometida, que responde al componente moral del conocimiento de enfermería e influye en las decisiones que ella debe tomar en torno al cuidado.

\section{Conocimiento emancipatorio:}

Este paradigma hace énfasis en el contexto histórico en que se realiza la acción, se esfuerza por mantener el conocimiento dentro del escenario en que nace, para confrontarlo con la práctica social (la devolución del conocimiento), mediante tácticas y estrategias de cambio (Vejarano, 1983).

Es a través del análisis de situaciones como la anteriormente descrita, que se ha intentado modificar los modelos de atención de Enfermería enfocados a condiciones más justas que de alguna manera favorece los resultados de las condiciones de salud de las persona.

\section{ANÁLISIS RELACIONADO CON LA TEORIA DE LOS CUIDADOS DE KRISTINE SWANSON}

Para la presente situación considero pertinente abordarla desde la perspectiva de la teoría de los cuidados de Kristine Swanson, la cual fue generada a partir de investigaciones fenomenológicas con mujeres que cursaron con pérdidas gestacionales, la utilidad de la teoría se ha demostrado en investigación, en educación y en la práctica clínica. La teoría fue planteada en el año 1991, la autora concibe los cuidados como una forma educativa de relacionarse con un ser apreciado hacia el que se siente un compromiso y una responsabilidad personal. Propone cinco procesos básicos (Conocer, estar con, hacer por, posibilitar y mantener las creencias).

Conocer: este concepto establece un compromiso profesional de explorar en el otro los requerimientos de cuidado. es esforzarse por comprender el significado de un suceso en la vida del otro, evitando conjeturas, centrándose en la persona a la que se cuida, buscando un proceso de compromiso entre el que cuida y el que es cuidado (Báez-Hernández, Nava-Navarro, Ramos-Cedeño y Medina. López, 2009). En la narrativa la enfermera direcciona el cuidado teniendo en cuenta el conocimiento que tiene de la persona; el conocer a María le permite ofrecer acciones coherentes con las necesidades de cuidado y acordes a sus expectativas y creencias.

Estar con: significa estar emocionalmente presente con el otro. Incluye estar allí en persona, trasmitir disponibilidad $\mathrm{y}$ 
compartir sentimientos sin abrumar a la persona cuidada. Asegura a la persona que su realidad es apreciada y que la enfermera está lista y dispuesta a ofrecer apoyo. En la situación narrada la enfermera se esmeró porque la mujer se sintiera verdaderamente apoyada, permito que la paciente pudiese expresar cuál era su necesidad más sentida en ese momento.

Hacer por: significa hacer por otros lo que se haría por uno mismo si fuera posible. Incluye adelantarse a las necesidades, confrontar, actuar con habilidad y competencia, proteger al que es cuidado respetando su dignidad. Involucra acciones por parte de la enfermera en beneficio del bienestar de la persona, que tienen la intención final de preservar la totalidad del otro. En la situación vemos como la enfermera no sólo proporciono a la paciente cuidado físico y poniendo en práctica su conocimiento en lo científico, si no que fue más allá de esto pude reconocer en ella otra necesidad desde lo emocional y espiritual.

Posibilitar: implica informar, explicar, apoyar, empoderar, generar alternativas. La enfermera permite que la mujer exprese sus sentimientos y sus necesidades, la apoya y le explica su situación de salud y genera alternativa para que ella satisfaga la necesidad más sentida en ese momento.

Mantener la creencia: significa promover en el otro una actitud de esperanza, de aceptación del cambio de roles. Implica sostener la fe y las capacidades que el otro tiene para sobreponerse a eventos o a una transición y afrontar el futuro con un nuevo sentido que inicia y se mantiene con el cuidado de enfermería (Swanson K., 1999). En la narrativa se puede apreciar que la enfermera enfoca el mantener la confianza en la fe; además, muestra actitud de esperanza y optimismo frente a la situación. Utiliza las creencias religiosas como estrategia de afrontamiento al suceso que está viviendo.

\section{CONCLUSIONES}

P Aunque el dolor por la pérdida de un ser querido es una de las experiencias comunes de la vida, siempre desencadena en las personas diversas reacciones generando en algunos casos dolor, miedo, angustia, culpabilidad, rabia, impotencia. Es así como la enfermera, debe prepararse para apoyar a las personas que viven la pérdida de un hijo, con conocimientos científicos, éticos, humanísticos, en ese sentido, aplicar una teoría de enfermería permite sustentar la práctica de manera coherente y trascendente para el sujeto de cuidado.

Acompañar y cuidar a los padres que han sufrido una pérdida perinatal no es algo que deba improvisarse, por lo que es necesaria una formación específica sobre duelo perinatal, habilidades de comunicación y técnicas de relación de ayuda. La formación es la clave que permitirá a los profesionales de la salud gestionar de un modo constructivo el soporte que se le pueda ofrecer a la familia que enfrenta la pérdida de un hijo.

La enseñanza principal de esta situación de enfermería fue aprender a estar, aprender a escuchar, comprender y respetar el dolor experimentado por una mujer al perder su hija, permitiendo una comunicación autentica entre el que cuida y el sujeto de cuidado.

La narrativa es un elemento importante, que permite comunicar momentos de gran significancia en la labor que como enfermeras realizamos diariamente, la vivencia de acompañamiento a una mujer en 
momentos de duelo puede ser enriquecedora para colegas, que en ocasiones se enfrentan a una situación similar y por desconocimiento no saben cómo actuar frente al fenómeno.

\section{BIBLIOGRAFÍA}

- Báez-Hernández, F., Nava-Navarro, V., RamosCedeño, L., y Medina. López, O. (2009). El significado de cuidado en la práctica profesional de enfermería. Rev Aquichan, 9(2), 43-49.

- Bourne, S. (1968). The psychological effects of stillbirths on women and their doctors. J R Coll Gen Pract, 16, 103-112.

- Carper, B. (1978). Fundamental patterns of knowing in nursing. Adv Nurs Sci. 1,13-23.

- Chinn, P., y Kramer, M. (1999). Theory and nursing, 5th Ed., St. Louis: Mosby.

- Duran, M. M. (2016). Marco epistemológico de la enfermería. Aquichan, 2 (2), 7-18. Recuperado de http://aquichan.unisabana.edu.co/index.php/aquicha n/article/view/17/34.

- Elia, A. D. (1959). The management of grief situations in obstetrics. BMQ0, 10, 6-12.
- Ilse. S. (1999). Brazos Vacíos: Cómo Vivir con el Aborto, la Muerte Prenatal y la Muerte Infantil. NY: Winter Green Press.

- Kennell, J.H., Slyter, H. \&Klaus, M.H. (1970). The mourning response of parents to the death of a newborn infant. $N$ Engl J Med. 283, 344-9.

- Kirkley-Best, E, Kellner, K.R. (1982). The forgotten grief: a review of the psychology of stillbirth. Am J Orthopsychiatry, 52, 420-9.

- López García, A.P. Duelo perinatal: Un secreto dentro de un misterio. Rev. Asoc. Esp. Neuropsiq., 2011; 31 (109), 53-70.

- Maroto N G, García C M, Mateo R I. 2004. El reto de la maternidad en España: dificultades sociales y sanitarias. Gaceta Sanitaria. 18 (Supl. 2): 13-23.

- Swanson, K. (1998). Desarrollo Empírico de una Teoría de Mediano Rango. Nursing Reesearch. 40(30), 22-28.

- Swanson, K. M. (1993). Image. Nursing scholarship. 25(4), 352-357.

- Swanson, K.M. (2007). Teoría de los cuidados, En: Tomey, A. Marriner A \& Alligood (Eds.). Modelos y Teorías de Enfermería. Madrid: Elsevier, pp. 766-773.

- Vejarano, M. (1983). La investigación participativa en América Latina. Antología. Pátzcuaro, Michoacán, México: Biblioteca Digital. Recuperado de http://tariacuri.crefal.edu.mx. 